\title{
Genetic characterization of Gaddi goat breed of Western Himalayas using microsatellite markers
}

\author{
Gurdeep Singh ${ }^{1}$, Yashpal Thakur ${ }^{1}$, Amitoz Kour ${ }^{2}$, Varun Sankhyan ${ }^{1}$ and Sanjeet Katoch ${ }^{1}$
}

1. Department of Animal Genetics and Breeding, CSK Himachal Pradesh Krishi Vishvavidyalaya, College of Veterinary and Animal Sciences, Holta, Palampur - 176 062, Himachal Pradesh, India; 2. Department of Veterinary Microbiology, CSK Himachal Pradesh Krishi Vishvavidyalaya, College of Veterinary and Animal Sciences, Holta, Palampur - 176062 , Himachal Pradesh, India.

Corresponding author: Gurdeep Singh, e-mail: gurdeepsingh443@yahoo.com, YT: ypthakur@rediffmail.com, AK: amitozkaur78@gmail.com, VS: sankhyan@gmail.com, SK: Skatoch@gmail.com

Received: 02-12-2014, Revised: 19-03-2015, Accepted: 26-03-2015, Published online: 22-04-2015

doi: 10.14202/vetworld.2015.527-531. How to cite this article: Singh G, Thakur Y, Kour A, Sankhyan V, Katoch S (2015) Genetic characterization of Gaddi goat breed of Western Himalayas using microsatellite markers, Veterinary World 8(4); 527-531.

\begin{abstract}
Aim: In the present study, genetic characterization of Gaddi goat breed, a native to north temperate western Himalayan region of India, was carried out for the purpose of breed characterization and assessing existing intra-population genetic diversity.

Materials and Methods: Totally, 75 blood samples procured at random from genetically unrelated animals of two sexes and different age groups and true to breed type were collected from different locations in the breeding tract of these goats in Himachal Pradesh, of which only 51 samples with desired quantity and quality were subjected to further processing for DNA isolation. The multi-locus genotype data were generated on 51 Gaddi goats sampled across different regions of the breeding tract in Himachal Pradesh using 15 FAO recommended goat specific microsatellite markers, which gave amplification and observed and effective number of alleles, gene frequency, observed and expected heterozygosity were estimated through PopGene software (1.3.1).

Results: A total of 135 distinct alleles were observed with mean observed and effective number of alleles as $9.0000 \pm 0.82$ and $6.5874 \pm 0.56$ respectively across all 15 studied loci. The maximum (15) alleles were contributed by loci DRBP1 and P19/DYA and the least (5) by SRCRSP5. The mean heterozygosity was observed to be $0.8347 \pm 0.01$ ranging from 0.7584 (SRCRSP5) to 0.9156 (P19-DYA) across all loci. The mean observed $\left(\mathrm{H}_{\mathrm{O}}\right)$ and expected $\left(\mathrm{H}_{\mathrm{E}}\right)$ heterozygosities across all loci were $0.7484 \pm 0.02$ and $0.8431 \pm 0.01$ respectively. The polymorphism information content (PIC) value ranged from 0.7148 (SRCPS5) to 0.909 (P19-DYA) with mean PIC of $0.8105 \pm 0.01$ in the present study. The average heterozygosity was observed to be $0.8347 \pm 0.01$ ranging from 0.7584 (SRCRSP5) to 0.9156 P19 (DYA) across all loci.

Conclusion: Microsatellite analysis revealed high level of polymorphism across studied microsatellite markers and informativeness of the markers for genetic diversity analysis studies in Gaddi goats. This high level of polymorphism can be utilized to plan future association studies to exploit the uniqueness and adaptability of indigenous Gaddi goat breed of Western Himalayas. Most studied microsatellite markers had desired neutrality, thus proving to be good candidates for genetic characterization and diversity analysis in Gaddi breed of goats also.
\end{abstract}

Keywords: characterization, Gaddi goat, microsatellite markers, Western Himalayas.

\section{Introduction}

Indian goat breeds are recognized as an invaluable component of world's goat genetic resources. Of the total goat population, $92.76 \%$ of goats are found in Asia and Africa. China, India, Pakistan and Bangladesh possess 35.36, 25.46, 10.79 and 7.05\% of the total goat of Asia, respectively [1].

"Gaddi" also known as "White Himalayan goat" is the predominant goat breed of high altitude, Western temperate Himalayas with its true home tract in hills of Himachal Pradesh but distribution extending to adjoining hilly areas of Jammu and Kashmir and Uttrakhand [2]. In Himachal Pradesh, these goats are reared by traditional "Gaddi" shepherds, a distinct

Copyright: The authors. This article is an open access article licensed under the terms of the Creative Commons Attributin License (http:// creative commons.org/licenses/by/2.0) which permits unrestricted use, distribution and reproduction in any medium, provided the work is properly cited. tribe of nomadic pastoralists leading to its nomenclature as "Gaddi" breed. These goats are highly suited for prevalent migratory production system as practiced by these pastoralists since ages. Gaddi is a medium-sized goat usually with white coat color, long horns, long drooping ears and convex nose line. The breed is amply described in terms of its geographical distribution, morphological characteristics, production attributes and cytogenetic profile [2-4] but little information [5] is so far available on molecular genetic characteristics of the breed and intra-population genetic diversity analysis.

Microsatellites have been widely used at present as standard and efficient method to characterize genetic variation among breeds and to estimate genetic diversity [6] and as to assign individuals to a breed $[7,8]$. Microsatellite have proved to be efficient molecular tools for diversity analysis in farm animals due to their several advantages like 
random distribution across the genome, high degree of polymorphism, co- dominance, neutrality with respect to selection and possibility of automated scoring of genotypes and have been used to analyze genetic variations in cattle, sheep, goat, pigs, buffaloes, horses and chickens [9]. But, molecular characterization studies on Gaddi goat breed using microsatellite markers are also limited [5,10]. Microsatellites, also known as simple sequence repeats or short tandem repeats, are tandemly repeating sequences of 2-6 bp of DNA, which have been demonstrated to be polymorphic in a number of eukaryotic genome [11]. Since microsatellites are polymorphic, they act as extremely useful markers for comparative study of genetic variation, parentage estimation, linkage map analysis and could well be the marker of choice for analysis of population structure in both wild [12] and domesticated [13] species.

The present study was therefore undertaken to genetically characterize Gaddi goat germplasm using suitable goat specific microsatellite markers for analyzing the prevalent genetic diversity within existing breed population, a pre-requisite for undertaking future genetic improvement and breed conservation program for the breed.

\section{Materials and Methods}

\section{Ethical approval}

During collection of blood samples from goats, attention had been paid to minimize pain to the animals and all the samples collection was carried out in accordance with the guidelines laid down by the International Animal Ethics Committee and prevailing local laws and regulations. The approval for carrying out this study was taken from the Institutional Animal Ethics Committee.

\section{Collection of blood samples}

Totally, 75 venous blood samples were collected at random from genetically unrelated animals of Gaddi goat breed belonging to either sex or different age groups from its from different locations of the natural breeding tract (Kullu, Kangra Mandi, Bilaspur Chamba, Kinnaur, lahaul and Spiti, adjoining areas of Palampur and other districts of Himachal Pradesh as shown in Figure-1.

\section{Isolation of DNA samples}

Of these, 51 blood samples with desired quantity up to $5-10 \mathrm{ml}$ and quality ensuring unrelatedness from different individuals such that the genomic DNA isolated was of high molecular weight $(>100-150 \mathrm{~kb})$ and free from impurities like RNA, protein, organic solvent or salt and thus further processed for DNA isolation by phenol-chloroform extraction method [14]. The quality of DNA was assessed through $0.7 \%$ horizontal mini-submarine agarose gel electrophoresis. The purity of DNA was assessed by calculating ratio of optical densities at $260 \mathrm{~nm}$ and $280 \mathrm{~nm}$. The samples with OD ratio (OD260/OD280) ranging from 1.7

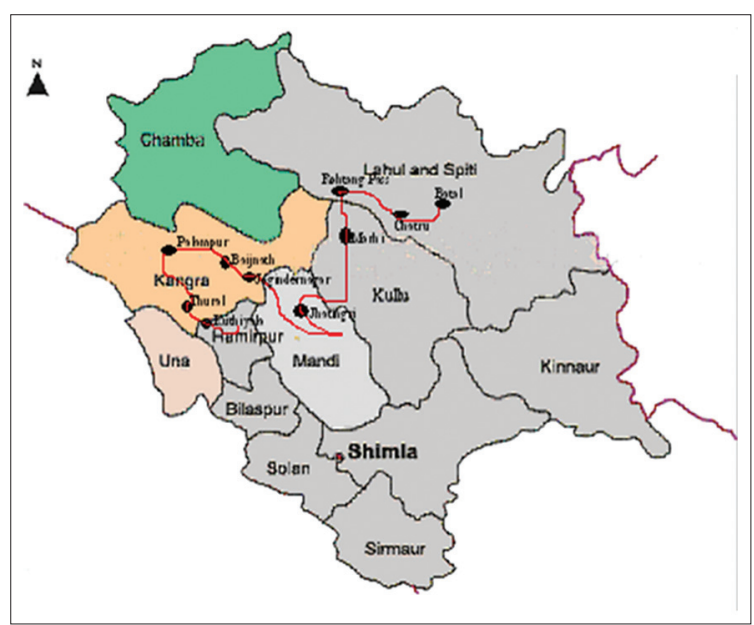

Figure-1: Migratory route along with distribution of Gaddi goat in Himachal Pradesh.

to 1.9 was used in subsequent experiments and without any smear in $0.7 \%$ agarose gel electrophoresis.

\section{Primer preparation}

15 FAO (DADIS MoDAD) recommended goat specific microsatellite markers selected from the list of 30 heterologous primers recommended for goat genetic diversity analysis namely ILSTS005, TGLA53, ETH10, OarFCB48, MAF70, ILSTS029, SRCRSP5, BM6444, INRABERN172, MAF065, DRBPP1, P19 (DYA), OarAE54, SPS113, TRBV6 (Table-1), which gave amplification were included in the analysis.

\section{Processing of DNA samples}

The microsatellite loci were amplified in programmable thermal cycler (Bio-Rad, S 1000) after optimization. The polymerase chain reaction (PCR) program used involved initial denaturation at $94^{\circ} \mathrm{C}$ for $3 \mathrm{~min}$ and 30 cycles of denaturation at $94^{\circ} \mathrm{C}$ for $30 \mathrm{~s}$, annealing for $45 \mathrm{~s}$, extension at $72^{\circ} \mathrm{C}$ for $45 \mathrm{~s}$ and final extension at $72^{\circ} \mathrm{C}$ for $10 \mathrm{~min}$. Documentation of PCR product was done in $1.5 \%$ agarose gel electrophoresis at $2-5 \mathrm{v} / \mathrm{cm}$. The PCR products for different microsatellite loci were resolved on $6 \%$ denaturing (urea) polyacrylamide gels along with 50 and 100 bp DNA ladders at 40-45 w. Microsatellite alleles were visualized by silver staining.

\section{Statistical analysis}

The microsatellite genotype data were analyzed using PopGene version (1.3.1) software to calculate allele frequencies, observed and effective number of alleles, observed and effective heterozygosities and polymorphism information content (PIC) in the population.

\section{Result and Discussion}

Various measures of genetic diversity obtained in the present study with Gaddi goats are presented in Table-2. All 15 microsatellite loci that have been identified to be polymorphic in a variety of domestic goats [15-21] amplified successfully in Gaddi breed 
Table-1: Primer characteristics of 15 microsatellite loci amplified in Gaddi goats.

\begin{tabular}{|c|c|c|c|}
\hline \multirow[t]{3}{*}{ Marker } & Primer sequence $\left(5 \rightarrow 3^{\prime}\right)$ & Base pairs & \multirow{3}{*}{$\begin{array}{c}\text { Optimized } \\
\text { annealing } \\
\text { temperature }\left({ }^{\circ} \mathrm{C}\right)\end{array}$} \\
\hline & Forward & $\mathbf{f}^{\prime}$ & \\
\hline & Reverse & $\mathbf{r}^{\prime}$ & \\
\hline \multirow[t]{2}{*}{ SRCRSP5 } & GGA CTC TAC CAA CTG AGC TAC AAG & 24 & 55 \\
\hline & TGA AAT GAA GCT AAA GCA ATG C & 22 & \\
\hline \multirow[t]{2}{*}{ ILSTS005 } & GGA AGC AAT TGA AAT CTA TAG CC & 23 & 55 \\
\hline & TGT TCT GTG AGT TTG TAA GC & 20 & \\
\hline \multirow[t]{2}{*}{ MAF065 } & AAA GGC CAG AGT ATG CAA TTA GGA G & 25 & 58 \\
\hline & CCA CTC CTC CTG AGA ATA TAA CAT G & 25 & \\
\hline \multirow[t]{2}{*}{ MAF70 } & CAC GGA GTC ACA AAG AGT CAG ACC & 24 & 65 \\
\hline & GCA GGA CTC TAC GGG GCC TाT GC & 23 & \\
\hline \multirow[t]{2}{*}{ OarFCB48 } & GAG TTA GTA CAA GGA TGA CAA GAG GCA C & 28 & 58 \\
\hline & GAC TCT AGA GGA TCG CAA AGA ACC AG & 26 & \\
\hline \multirow[t]{2}{*}{ OarAE54 } & TAC TAA AGA AAC ATG AAG CTC CCA & 24 & 58 \\
\hline & GGA AAC ATT TAT TCT TAT TCC TCA GTG & 27 & \\
\hline \multirow[t]{2}{*}{ SPS113 } & ССT CCA CAC AGG CTT CTC TGA CTT & 24 & 58 \\
\hline & ССT AAC TTG CTT GAG TTA TTG CCC & 24 & \\
\hline \multirow[t]{2}{*}{ INRABERN172 } & CCA CTT CCC TGT ATC СTC CT & 20 & 58 \\
\hline & GGT GCT CCC ATT GTG TAG AC & 20 & \\
\hline \multirow[t]{2}{*}{ ILSTS029 } & TGT TIT GAT GGA ACA CAG & 18 & 55 \\
\hline & TGG ATT TAG ACC AGG GTT GG & 20 & \\
\hline \multirow[t]{2}{*}{ TGLA53 } & GCT TTC AGA AAT AGT TTG CAT TCA & 24 & 55 \\
\hline & ATC TTC ACA TGA TAT TAC AGC AGA & 24 & \\
\hline \multirow[t]{2}{*}{ BM6444 } & CTC TGG GTA CAA CAC TGA GTC C & 22 & 65 \\
\hline & TAG AGA GTT TCC CTG TCC ATC C & 22 & \\
\hline \multirow[t]{2}{*}{ ETH10 } & GTT CAG GAC TGG CCC TGC TAA CA & 23 & 55 \\
\hline & ССT CCA GCC CAC TाT СТС ТTC TC & 23 & \\
\hline \multirow[t]{2}{*}{ TCRVB6 } & GAG TCC TCA GCA AGC AGG TC & 20 & 55 \\
\hline & CCA GGA ATT GGA TCA CAC CT & 20 & \\
\hline \multirow[t]{2}{*}{ DRBP1 } & ATG GTG CAG CAG CAA GGT GAG CA & 23 & 58 \\
\hline & GGG ACT CAG TCT CTC TAT CTC TIT G & 25 & \\
\hline \multirow[t]{2}{*}{ P19 (DYA) } & AAC ACC ATC AAA CAG TAA GAG & 21 & 55 \\
\hline & CAT AGT AAC AGA TCT TCC TAC A & 22 & \\
\hline
\end{tabular}

as well and produced definite banding patterns from which individual genotypes could be ascertained.

A total of 135 distinct alleles were detected (Table-2) over 15 studied microsatellite loci with a mean observed number of alleles $(\mathrm{Na})$ of $9.0000 \pm 0.82$ alleles per locus. The allele size ranged between $115 \mathrm{bp}$ (OarAE54) and $256 \mathrm{bp}$ (INRABERN172). These microsatellites exhibited a high level of polymorphism as revealed by a wide range of alleles varying from 5 (SRCRSP5) to 15 (DRBP1 and P19 [DYA]). The mean effective number of alleles (Ne) was $6.5874 \pm 0.56$. The mean effective number of alleles was less than the observed values across all loci and ranged from 4.1384 (SRCRSP5) to 11.8497 in P19 (DYA). The overall allelic diversity considered to be a reasonable indicator of genetic variation within the population $[4,9,22]$ displayed high genetic variation in Gaddi goat breed. The FAO had specified at least 4 distinct alleles per locus for proficient judgment of genetic distance between breeds. Hence, all 15 microsatellite markers studied, exhibited ample polymorphism for evaluating intra-population genetic variability in Gaddi breed. The results obtained in Gaddi goats corroborated well with Kanniadu goat [23] who reported observed number of alleles between 5 (RM4) and 13 (RM088, OarE129) with mean value of $8.64 \pm 0.48$ and effective number of alleles from 1.45
(ILSTS34) to 7.89 (ILSTS033 and OMHC1) with mean value of $4.22 \pm 0.34$.

Heterozygosity is an appropriate measure of genetic variability within a population when populations are expanding. Therefore, heterozygosity values were used as an estimate for variability of studied goat population. The observed and expected heterozygosity values on the basis of allele frequency are also given in Table-2. The mean observed and expected heterozygosities were $0.7484 \pm 0.02$ (range of 0.6200 (SPS113) to 0.9200 (INRABERN172)) and $0.8431 \pm 0.01$ (range of 0.7659 (SRCRSP5) to 0.9247 P19 (DYA)) respectively. Most of the loci showed relatively higher expected heterozygosity values that might be due to low selection pressure, large population size and immigration of new genetic materials.

The PIC values, which denotes the statistical assessment of informativeness of a marker were high and ranged from 0.7148 (SRCPS5) to 0.909 (P19 [DYA]) with mean PIC of $0.8105 \pm 0.01$ (Table-2). This may be due to the fact that there was increased level of heterozygosity and allele richness in the population which are the good indicators of genetic polymorphism in present study on Gaddi goats. These values are indicative of the fact that the markers used were highly informative for analysis of genetic diversity in Gaddi goat breed [24]. The genetic marker showing 


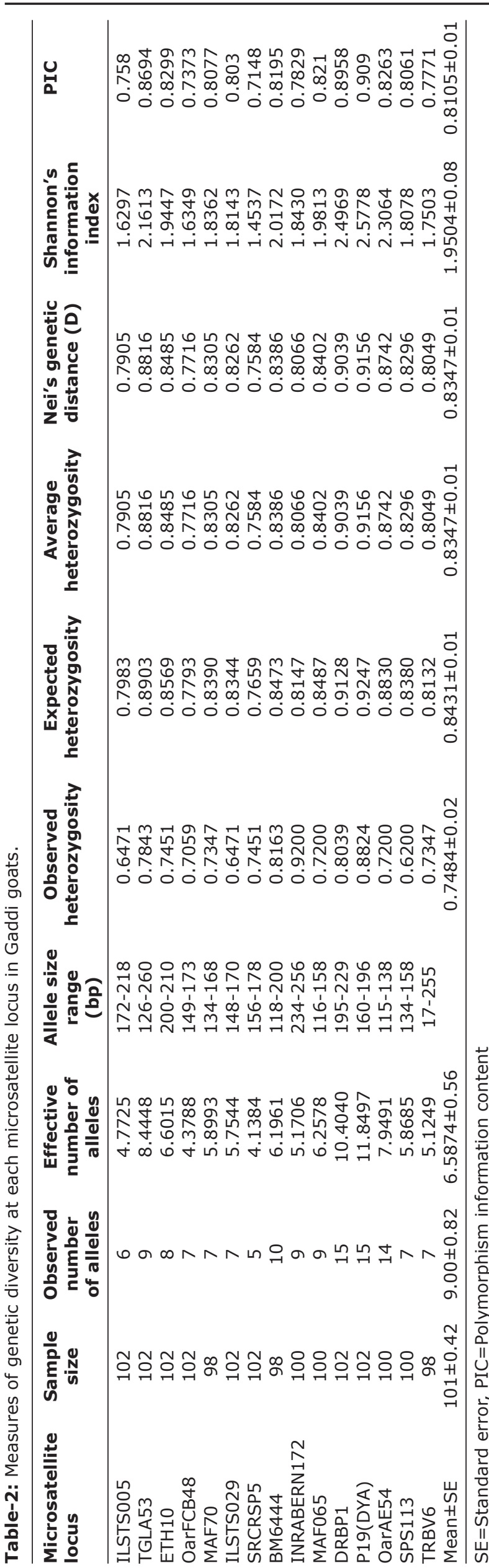

PIC values higher than 0.5 are normally considered as informative in population genetic analysis [25]. Mean PIC value of 0.48 , lower than the values obtained in the present study, was earlier reported in three Indian goat breeds (Sirohi, Jamunapari and Barbari) using cattle microsatellite markers [26]. The present PIC values were comparable with Chinese goat breeds (0.746-0.800) as reported by [27] using ovine microsatellite markers and mean value of 0.82 in Berari goats [28]. In contrast, [16] obtained lower PIC values for Korean (0.350), Chinese (0.620) and Saanen (0.570) goats. Further [21] reported PIC estimates ranging from 0.746 to 0.800 using ovine microsatellite markers that were comparable with Chinese goat breeds, and thus consistent with findings of the present study in Gaddi goats. Similarly [29] reported PIC values from 0.271 (OarJMP29) to 0.878 (ILSTS 082) in Sangamneri goats across loci with mean of 0.711 .

The genetic variability of a population is usually measured as average heterozygosity per locus while the gene differences between two populations may be measured by Nei's standard genetic distance. The values for these measures varied from 0.7584 (SRCRSP5) to 0.9156 P19 (DYA) with mean genetic distance of $0.8347 \pm 0.01$. The mean Shannon's index value was high $(1.9504 \pm 0.08)$ showing higher gene diversity in the existing population.

\section{Conclusion}

In the present investigation, an attempt has been made to genetically characterize "Gaddi" goat population in its breeding tract in HP using 15 FAO recommended goat specific microsatellite markers. Microsatellite analysis revealed high level of polymorphism and informativeness of studied microsatellite markers in genetic diversity analysis in Gaddi goats. The high PIC values as observed in the study are indicative of high informativeness of studied markers for genetic diversity analysis in Gaddi goat breed. Most studied microsatellite markers had desired neutrality, thus proving to be good candidates for genetic characterization and diversity analysis in Gaddi breed of goats also. The information gathered could be utilized to plan breeding, improvement and conservation programs for this valuable goat germplasm resource and future association studies to exploit its unique adaptability traits. The significant level of variability in this population reflects that the Gaddi goat population contains a valuable and substantial amount of genetic diversity among the studied breed and thus there is good scope for bringing effective genetic improvement, conservation and designing future breeding policies for these goats.

\section{Authors' Contributions}

GS and YT planned and designed the study. GS and AK collected the samples, GS and VS performed test and analyzed the data. All authors participated in 
draft and revision of the manuscript. All authors read and approved the final manuscript.

\section{Acknowledgments}

The authors owes sincere and earnest thanks to CSK Himachal Pradesh Krishi Vishvavidyalaya, Palampur, College of Veterinary and Animal Sciences and acknowledge the assistance of funds and farms involved and the technical support from staff to conduct the research work smoothly.

\section{Competing Interests} interests.

The authors declare that they have no competing

\section{References}

1. FAOSTAT. (2009) http://www.faostat3.fao.org. Last accessed on 18-11-2014.

2. Acharaya, R.M. (1982) Sheep and goat breeds of India. Animal Production And Health Paper, Paper No 30. FAO, Rome.

3. Bhatia, S. and Shankar, V. (1991) Cytogenetic analysis of gaddi goats. Indian J. Anim. Sci., 61: 646-648.

4. Gupta, K., Kaila, O.P. and Marwaha, C.L. (2005) Growth patterns of gaddi goats in cold arid zone of Himachal Pradesh. Indian J. Small Rumin., 11(2): 187-190.

5. Dixit, S.P., Verma, N.K., Aggarwal, R.A.K., Vyas, M.K., Jyoti, R. and Sharma, A. (2012) Genetic diversity and relationship among Indian goat breeds based on microsatellite markers. Small Rumin. Res., 105(1-3): 38-45.

6. Baumung, R., Simianer, H. and Hoffman, I. (2004) Genetic diversity studies in farm animals - A survey. J. Anim. Breed. Genet., 121: 361-373.

7. Maudet, C., Luikart, G. and Taberlet, P. (2002) Genetic diversity and assignment tests among seven French cattle breeds based on microsatellite DNA analysis. J. Anim. Sci., 80(4): 942-950.

8. Baudouin, L., Piry, S. and Cornuet, J.M. (2004) Analytical bayesian approach for assigning individuals to populations. J. Hered., 95(3): 217-224.

9. Boyce, W.M., Hedrick, P.W., Muggli-Cockett, N.E., Kalinowski, S., Penedo, M.C. and Ramey, R.R. (1996) Genetic variation of major histocompatibilty complex and microsatellite loci: A comparison in Bighorn sheep. Genetics., 145(2): 421-433.

10. Sharma, A., Dutt, G., Jayakumar, S., Saroha, V., Verma, N.K and Dixit, S.P. (2013) Genetic structuring of nine Indian domestic goat breeds based on SNPs identified in IGF-1 gene. Anim. Biotechnol., 24(2): 148-157.

11. Litt, M. and Lutty, J.A. (1989). A hypervariable microsatellite revealed by in vitro amplification of a dinucleotide repeats within the cardiac muscle actin gene. Am. J. Human Genet., 44(3): 397-401.

12. Scribner, K.T., Arntzen, J.W. and Burke, T. (1994) Comparative analysis of intra and interpopulation genetic diversity in buffalo, using allozyme, single-locus microsatellite, minisatellite, and multilocus minisatellite data. Mol. Biol. Evol., 11: 737-748.

13. Machugh, D.E, Loftus, R.T., Bradley, D.G., Sharp, P.M. and Cunningham, P. (1994) Microsatellite DNA variation within and among European cattle breeds. Proc. Biol. Sci., 256(1345): 25-31.

14. Sambrook, J., Fritsch, F. and Maniatis, T. (1989) Molecular Cloning: A Laboratory Manual. $2^{\text {nd }}$.ed. Cold Spring Harbour Cold Spring Laboratory Press, NY.

15. Soranzo, N., Provan, J. and Powell, W. (1999) An example of microsatellite length variation in the mitochondrial genome of conifers. Genome., 42(158-161): 0831-2796.

16. Kim, K.S., Yeo, J.S., Lee, J.W., Kim, J.W. and Choi, C.B. (2002) Genetic diversity of goats from Korea and China using microsatellite analysis. Asian-Aust. J. Anim. Sci., 15(4): 461-465.

17. Ouafi, A.T., Babilliot, J.M., Leroux, C. and Martin, P. (2002) Genetic diversity of the two main moroccan goat breeds: Phylogenetic relationships with four breeds reared in France. Small Rumin. Res., 45(3): 225-233.

18. Li, M.H., Li, K. and Zhao, S.H. (2004) Diversity of Chinese indigenous goat breeds: A conservation perspective. AsianAust. J. Anim. Sci., 17(5): 726-732.

19. Dixit, S.P., Verma, N.K., Ahlawat, S.P.S. and Aggarwal, R.A.K. (2008) Molecular genetic characterization of Kutchi breed of goat. Curr. Sci., 95(7): 946-952.

20. Rout, P.K., Joshi, M.B., Mandal, A., Laloe, D., Singh, L. and Thangaraj, K. (2008) Microsatellite based phylogeny of Indian domestic goats. BMC Genet., 9: 11.

21. Ramamoorthi, J., Thilagam, K., Sivaselvam, S.N. and Karthickeyan, S.M. (2009) Genetic characterization of barbari goats using microsatellite markers. J. Vet. Sci., 10(1): 73-76.

22. Rout, P.K, Thangraj, K, Mandal, A. and Roy, R. (2012) Genetic variation and population structure in Jamunapari goats using microsatellites, mitochondrial DNA, and milk protein genes. The Sci. World J., 2012: 618909.

23. Dixit, S.P., Verma, N.K., Aggarwal, R.A.K., Vyas, M.K., Rana, J., Sharma, A. and Chander. R. (2011) Genetic variability and bottleneck analyses of kanniadu goat breed based on microsatellite markers. Indian J. Anim. Sci., 81(1): 43-48.

24. Kemp, S.J. and Hishida, O. (1995) A panel of polymorphic bovine, ovine and caprine microsatellite markers. Anim. Genet., 26(5): 299-306.

25. Botstein, D., White, R.L., Skolnick, M. and Davis, R.W. (1980) Construction of a genetic linkage map in man using RFLP. Am. J. Human Genet., 32(3): 324-331.

26. Ganai, N.A. and Yadava, B.R. (2001) Genetic variation within and among three Indian goat breeds using heterologous microsatellite markers. Anim. Biotechnol., 12(2): 121-136.

27. Yang, L., Zhao, S.H., Li, K., Peng, Z.Z. and Montgomery, G.W. (1999) Determination of genetic relationships among five indigenous Chinese goat breeds with six microsatellites markers. Anim. Genet., 30(6): 452-455.

28. Mishra P, Ali, S.A, Kuralkar, V.S, Dixit, S.P, Aggarwal, K.A.R., Dangi, S.P. and Verma, K.N. (2013) Analysis of genetic diversity in berari goat population of Maharashtra state. Iranian J. Appl. Anim. Sci., 3(3): 553-559.

29. Verma, N.K., Dixit, S.P., Aggarwal, R.A.K., Dangi, P.S. and Joshi, B.K. (2010) Phenotypic and genetic characterization of sangamneri goat breed. The Indian J. Anim. Sci., 80: 1109-1114. 